\title{
Reduction of Uncertainties for Damage Identification of Bridge Based on Fuzzy Nearness and Modal Data
}

\author{
Hanbing Liu, Yubo Jiao, Yongchun Cheng, and Yafeng Gong \\ College of Transportation, Jilin University, Changchun 130022, China \\ Correspondence should be addressed to Yafeng Gong, jiaoyb@jlu.edu.cn
}

Received 17 November 2011; Accepted 13 March 2012

Academic Editor: Yehia Khulief

Copyright (C) 2012 Hanbing Liu et al. This is an open access article distributed under the Creative Commons Attribution License, which permits unrestricted use, distribution, and reproduction in any medium, provided the original work is properly cited.

To avoid the false results of deterministic identification methods induced by uncertainties, a fuzzy nearness-based method is proposed for the damage identification of bridge. An improved index based on ratios of modal shape components is used as identification measurements. The knowledge base for damage identification is established through corresponding relationship between fuzzified measurements and damage severities. The damage condition of test samples can be assessed based on approaching principle through fuzzy nearness with rules in knowledge base. A numerical analysis on a multigirder bridge considering uncertainty is presented to demonstrate the effectiveness of the proposed method. The results indicate that the fuzzy nearness-based method can achieve an accurate identification with success rate up to $93.75 \%$. Antinoise analysis and the ability for dealing with incomplete information reveal its robustness.

\section{Introduction}

Simply supported reinforced concrete bridge is the most widely used type for mediumsmall span bridges. The structures are exposed to various external loads such as traffic, temperature, material aging, and earthquakes during their service time. The damages inevitably occur in these structures, which may pose great threat to human life and property. Therefore, structural damage identification has became an important research topic [1,2].

Vibration-based damage identification methods rely on the fact that modal characteristics (frequency, mode shapes and modal damping) are functions of the physical properties (mass, stiffness) of structure. The modal characteristics used for damage detection include mode shapes, natural frequency, modal shape curvature, modal strain energy, modal flexibility, and so forth [3-7]. 
Among these modal characteristics, natural frequency is easy to obtain. However, the simply supported reinforced concrete bridges are spatial symmetric structures. Natural frequency cannot distinguish damage at symmetric locations in these symmetric structures [8].

Comparing with natural frequency, mode shape and its derivatives (modal shape curvature, modal flexibility, uniform load surface, etc.) are more sensitive to local damage. Pandey et al. [9] demonstrated that the absolute changes in curvature mode shapes can effectively locate the damage region for cantilever and simply supported beam model. The changes in the curvature mode shapes increase with increasing size of damage. This information can be used to obtain the amount of damage in the structure. Stubbs and Kim [10] presented a methodology to localize and estimate the severity of damage in structures for which only postdamage modal parameters are available for a few vibrational modes. Qiao et al. [11] presented a PZT-SLV and PZT-PVDF actuator-sensor systems coupled with curvature modal shape-based damage identification strategy for composite structures, and numerical simulation showed that the curvature modal shape exhibited good sensitivity to damage.

The uncertainties associated with the structure such as measurement noise can lead to unreliable damage detection. The primary uncertainty analysis methods used for damage detection of bridge include Monte-Carlo simulation, interval analysis, stochastic finite element analysis, and so forth [12-14]. In recent years, fuzzy logic-based method for dealing with uncertainties has become widely applied for its easier understanding. Ganguli et al. $[8,15-17]$ adopted the natural frequency and modal shape curvature as the input of fuzzy logic systems and genetic fuzzy logic systems for the damage detection of helicopter rotor blades. Zhao and Chen [18] proposed a method based on principal component analysis and fuzzy logic systems for the damage detection of concrete bridges. Reda and Lucero [19] introduced new techniques based on Bayesian updating and fuzzy sets to improve pattern recognition and damage detection of structures. Among these methods, they are mainly based on fuzzy inference, which can realize the identification through fuzzification, fuzzy inference, and deffuzzification. Comparing with fuzzy inference, fuzzy nearness-based damage identification method is more easily implemented, and it has not been reported in the literature.

In this paper, the implementation process of damage identification using fuzzy nearness and approaching principle is presented. A numerical simulation of simply supported bridge with multiple girders is carried out, and the feasibility of the proposed method is discussed.

\section{Theoretical Background}

\subsection{Dynamics Background}

The governing equation of motion for free vibration analysis of an Euler-Bernoulli beam structure without considering damping is as follows [20]:

$$
\frac{\partial^{2}}{\partial x^{2}}\left[E I(x) \frac{\partial^{2} u(x, t)}{\partial x^{2}}\right]+m(x) \frac{\partial^{2} u(x, t)}{\partial t^{2}}=0
$$

where $E I(x)$ is the flexural rigidity of the beam, $m(x)$ is mass per unit length of the beam, and $u(x, t)$ is the transverse displacement of the beam reference axis. The beam equation is 
solved for natural frequencies using the finite element method. The beam is discretized into a number of beam finite elements, with transverse displacement and slope as nodal degrees of freedom and cubic interpolation functions.

For an $n$ degree of freedom system, the equation of motion in discrete form is obtained after assembling of the element matrix and application of the boundary conditions:

$$
M \ddot{q}+K q=0 .
$$

Here $M$ is the $n \times n$ mass matrix of the system, $K$ is the $n \times n$ stiffness matrix of the system, and $q$ is the $n \times 1$ vector of nodal displacements. We seek a solution of the form $q=\phi e^{(i w t)}$, which results in the eigenvalue problem:

$$
K \phi=\omega^{2} M \phi
$$

Solving this eigenvalue problem, we get $n$ eigenvalues $(\omega)$ and $n$ eigenvalues $(\phi)$ which represent the natural frequencies and mode shapes of the system, respectively.

\subsection{Ratios of Mode Shape Components as Damage Indicator}

Mode shape is more sensitive to local damage, and it can identify the damage at symmetric locations for symmetric structures. So the ratios of mode shape components are used as the indicator for the symmetric cases of simply supported bridge. It can be expressed as follows:

$$
\overline{\Delta \phi_{n}^{m}}=\frac{\phi_{\mathrm{dn}}^{m}}{\phi_{\mathrm{un}}^{m}} .
$$

Here $\overline{\Delta \phi_{n}^{m}}$ is the ratios of mode shape components, $m$ is the mode number, $n$ is the node number, and $\phi_{\mathrm{dn}}^{m}, \phi_{\mathrm{un}}^{m}$ are the mode shape value of undamaged and damaged structure for the $n$th node of the $m$ th mode, respectively.

In this paper, an improved index based on ratios of mode shape components between before and after damage is constructed as the input of fuzzy systems.

The mode shape ratios can be further transformed as follows:

$$
\Delta \phi_{n}^{m}=\left|\left(\overline{\Delta \phi_{n}^{m}} * 1000-1000\right)\right|,
$$

where $\Delta \phi_{n}^{m}$ is the improved mode shape ratio (IMSR) which is used as the damage indicator in this paper and $\overline{\Delta \phi_{n}^{m}}$ is the mode shape ratio.

\subsection{Modeling of Damage}

The damage of structure is represented by reduction in the element stiffness and the damage parameter in percentage, and $D$ is defined by

$$
D=\frac{100\left(E^{u}-E^{d}\right)}{E^{u}} .
$$


Here $E$ is Young's modulus of the bridge material and the superscripts $u$ and $d$ represent undamaged and damaged, respectively.

\subsection{Modeling of Uncertainty}

Uncertainties inevitably exist in experimental data due to modeling and measurement errors. The noise-contaminated damage indicator $\left(\Delta \phi_{\text {noise }}\right)$ can be obtained after adding measurement noise into the calculated indicator $(\Delta \phi)$

$$
\Delta \phi_{\text {noise }}=\Delta \phi(1+\lambda \times \operatorname{normrnd}(0,1)) .
$$

Here $\Delta \phi_{\text {noise }}$ is the change rate of mode shape ratio with noise, while $\Delta \phi$ is the change rate of mode shape ratio without noise, $\lambda$ is the noise level, and normrnd $(0,1)$ is gaussian random number.

\subsection{Fuzzy Nearness and Approaching Principle}

\subsubsection{Fuzzy Nearness}

Given that $A$ and $B$ are fuzzy sets in domain $F(U)$, denoted by $A, B \in F(U)$, the inner and outer products between $A$ and $B$ are defined by

$$
\begin{aligned}
& A \bullet B=\triangleq \underset{x \in U}{\vee}\left(\mu_{A}(x) \wedge \mu_{B}(x)\right), \\
& A \otimes B=\triangleq \hat{\vartheta}_{x \in U}\left(\mu_{A}(x) \vee \mu_{B}(x)\right) .
\end{aligned}
$$

Here $A \bullet B$ and $A \otimes B$ are, respectively, the inner and outer product, $\mu_{A}(x)$ and $\mu_{B}(x)$ are, respectively, the membership function of $A$ and $B$, while the symbols $\vee$ and $\wedge$ are, respectively, to obtain maximum and minimum value.

The fuzzy nearness between $A$ and $B$ is defined by

$$
(A, B)=\frac{1}{2}[A \bullet B+A \otimes B],
$$

where $(A, B)$ is the fuzzy nearness between $A$ and $B .0 \leq(A, B) \leq 1$, and the bigger $(A, B)$ is, the better the nearness between $A$ and $B$ is.

\subsubsection{Approaching Principle}

Given that $A_{1}, A_{2}, \ldots A_{n} \in F(U)$ are the fuzzy sets. For fuzzy set $B$, if $\exists i \in\{1,2, \ldots, n\}$, $\left(B, A_{i}\right)=\max _{1 \leq j \leq n}\left(B, A_{j}\right)$, then the nearness between $A_{i}$ and $B$ is better, and fuzzy set $B$ can be classified into fuzzy set $A_{i}$. 


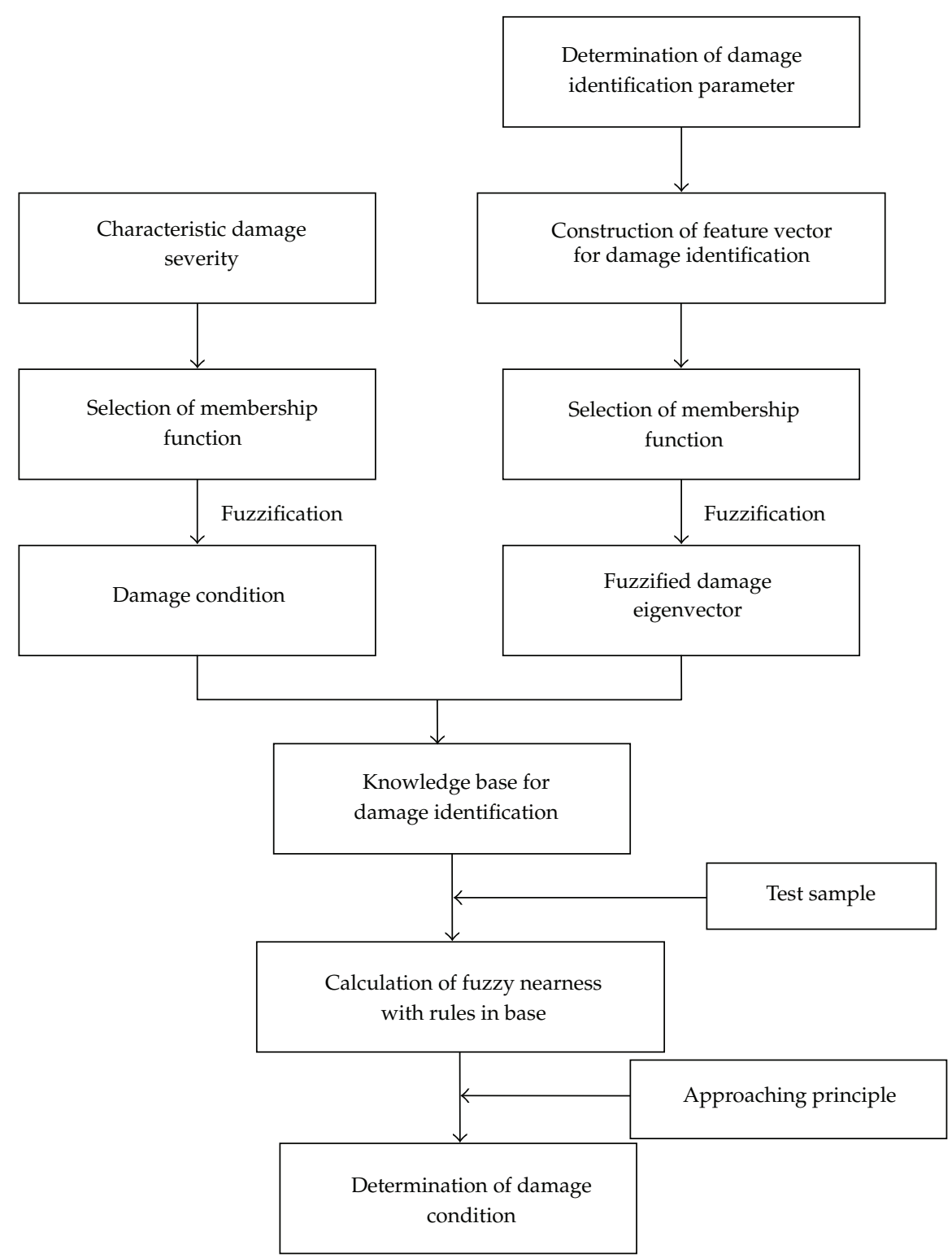

Figure 1: Calculation process for damage identification based on fuzzy nearness and approaching principle.

\subsection{Damage Identification Strategy Based on Fuzzy Nearness and Approaching Principle}

\subsubsection{Calculation Process}

The calculation process for damage identification of bridge based on fuzzy nearness and approaching principle proposed in this paper is illustrated in Figure 1. 


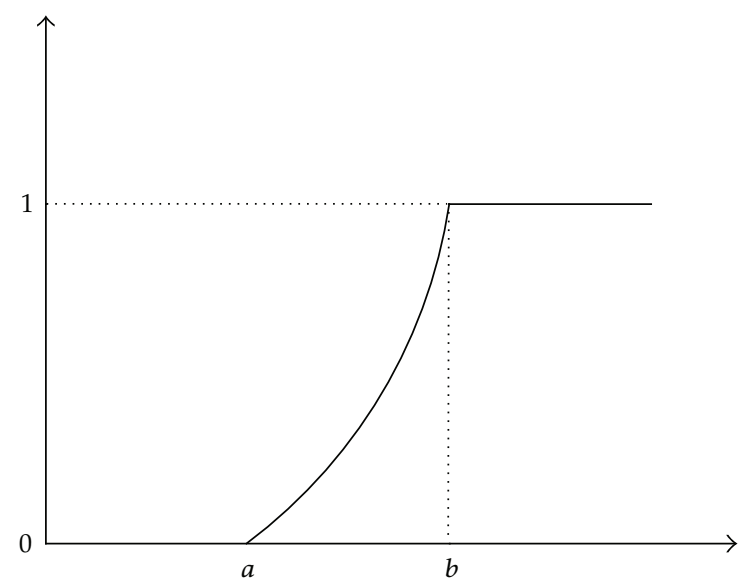

Figure 2: Membership function used for eigenvector of IMSR.

\subsubsection{Fuzzification of Feature Vector for Damage Identification}

The IMSR (defined in (2.5)) is used as the damage identification parameter in this paper, and the vector of IMSR at characteristic nodes of bridge is regarded as the eigenvector. Considering the IMSR at each node increases with the damage severity, the parabola function is selected as the membership function of eigenvector.

The membership function used for eigenvector of IMSR can be defined using the following equation:

$$
\mu(x)=\left(\frac{x-a}{b-a}\right)^{K}, \quad a \leq x \leq b .
$$

The parameters $a, b$ are shown in Figure 2.

\subsubsection{Fuzzification of Damage Severities}

In this paper, the damage in each element is modeled by stiffness reduction of $5 \%, 10 \%, 15 \%$, and $20 \%$, respectively. These damage conditions are classified as "slight damage," "moderate damage," "severe damage," and "catastrophic damage," respectively. Damage condition below "slight damage" is classified as "undamaged".

The membership function used for damage severities can be defined using the following equation:

$$
\mu(y)=\frac{1}{1+|(y-c) / a|^{2 b}}
$$

where $[a, b, c]$ are the variables that control the shape of the function. And it is shown in Figure 3. 


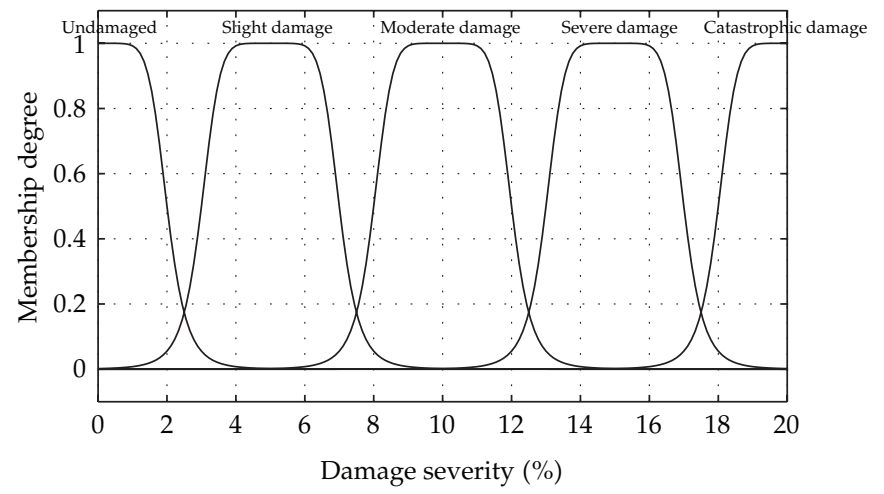

Figure 3: Schematic diagram of membership function for damage severity.

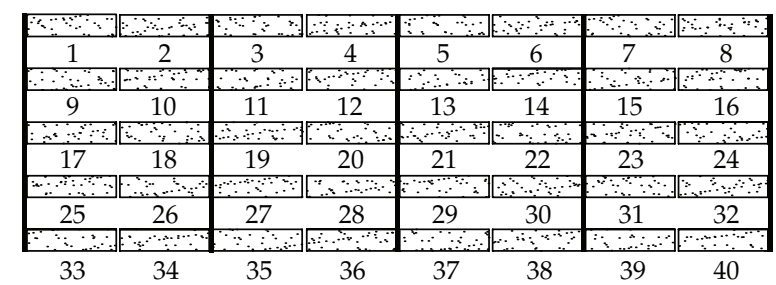

Figure 4: A bridge with multiple girders and element numbers.

Table 1: Material properties of the simply supported bridge.

\begin{tabular}{lc}
\hline Material parameters & Values \\
\hline Young's modulus $(E)$ & $3.3 \times 10^{10} \mathrm{~N} / \mathrm{m}^{2}$ \\
Poisson's ratio & 0.1667 \\
Mass density & $2600 \mathrm{~kg} / \mathrm{m}^{3}$ \\
Moment of inertia & $0.35 \mathrm{~m}^{4}$ \\
\hline
\end{tabular}

\section{Numerical Simulation}

\subsection{Modeling of Simply Supported Bridge}

A numerical analysis is performed on a simply supported bridge with multiple girders to investigate the effectiveness of the proposed strategy. The bridge, which consists of five girders and diaphragms, is modeled using beam elements as shown in Figure 4 [21]. The beam elements have equal length $(l=2.5 \mathrm{~m})$ with uniform flexural rigidity. The relevant properties of the bridge are shown in Table 1.

\subsection{Modal Shape Curvature-Based Damage Localization}

Under the effect of shear force and bending moment, the elements near bearing and midspan are susceptible to damage. Taking the identification of element 4 , for example, the suspicious damaged elements are detected based on the method proposed by Liu et al. [21] as shown in Figure 5, and Table 2. 


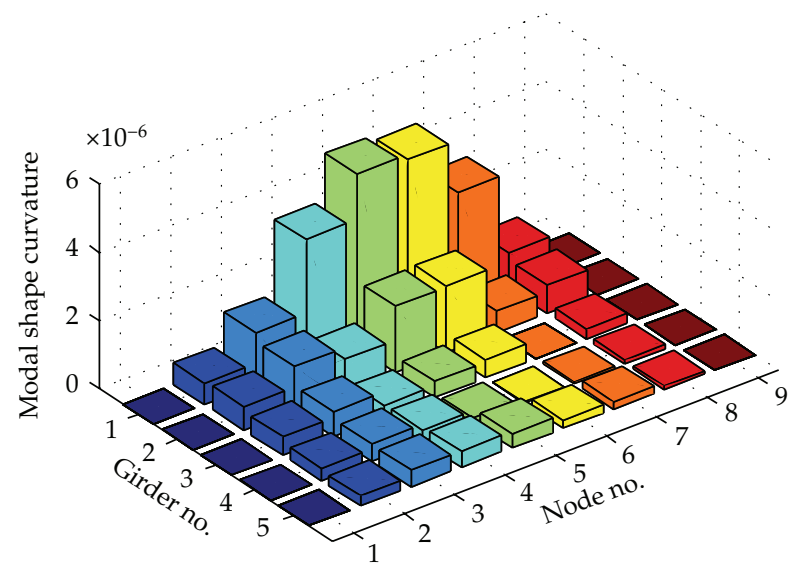

Figure 5: Identification results of element 4.

Table 2: The identified suspicious damaged elements.

Damaged element

Suspicious damaged elements

\subsection{Fuzzy Nearness-Based Damage Identification for Simply Supported Bridge}

\subsubsection{Eigenvector for Damage Identification}

The proposed parameter IMSR is used as the identification index, and the vector of IMSR for the first vertical bending mode at characteristic nodes of bridge is regarded as the eigenvector. There are totally 45 nodes for the simply supported bridge. It is unnecessary to use the IMSR of all nodes. In this paper, the IMSR of midspan nodes of five girders and the nodes relevant to the suspicious damaged elements are selected as the eigenvector for the damage identification. The nodes used for the fuzzy nearness-based system of element 4 are shown in Figure 6.

In the process of numerical simulation, it is found that the changes of IMSR at node 23 induced by damage of element 4 is slight. Therefore, the eigenvector used for damage identification is as follows:

$$
x=\left\{\Delta \phi_{4}^{1}, \Delta \phi_{5}^{1}, \Delta \phi_{6}^{1}, \Delta \phi_{14}^{1}, \Delta \phi_{32}^{1}, \Delta \phi_{41}^{1}\right\},
$$

where the superscript represents the first-order vertical bending mode used in this paper, and the subscript represents the node number.

\subsubsection{Knowledge Base for Damage Identification}

The fuzzy nearness-based knowledge base for damage identification is listed in Table 3 which is constructed according to Figure 1. 


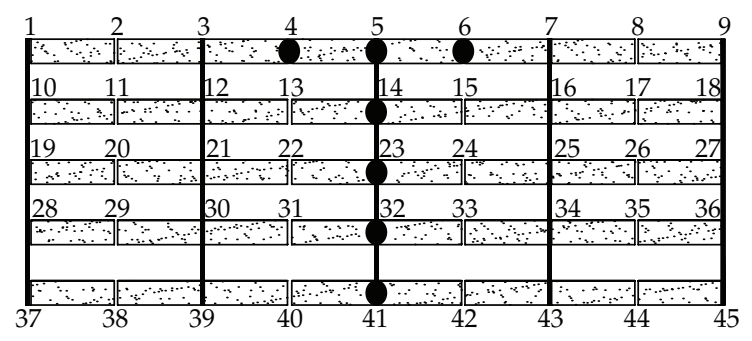

Figure 6: Characteristic nodes for the damage identification of element 4 .

Table 3: Knowledge base for damage identification of element 4.

\begin{tabular}{lccccccc}
\hline $\begin{array}{l}\text { Slight } \\
\text { damage }\end{array}$ & $\begin{array}{c}\text { Moderate } \\
\text { damage }\end{array}$ & $\begin{array}{c}\text { Severe } \\
\text { damage }\end{array}$ & $\begin{array}{c}\text { Catastrophic } \\
\text { damage }\end{array}$ & $\begin{array}{c}\text { Slight } \\
\text { damage }\end{array}$ & $\begin{array}{c}\text { Moderate } \\
\text { damage }\end{array}$ & $\begin{array}{c}\text { Severe } \\
\text { damage }\end{array}$ & $\begin{array}{c}\text { Catastrophic } \\
\text { damage }\end{array}$ \\
\hline 0.1080 & 0.3177 & 0.6169 & 1 & 0.1048 & 0.3245 & 0.6138 & 1 \\
0.1051 & 0.3185 & 0.6144 & 1 & 0.1051 & 0.3185 & 0.6144 & 1 \\
0.1048 & 0.3245 & 0.6138 & 1 & 0.1080 & 0.3177 & 0.6169 & 1 \\
0.1125 & 0.3181 & 0.6213 & 1 & 0.1125 & 0.3181 & 0.6213 & 1 \\
0.1073 & 0.3199 & 0.6183 & 1 & 0.1073 & 0.3199 & 0.6183 & 1 \\
0.1062 & 0.3194 & 0.6224 & 1 & 0.1062 & 0.3194 & 0.6224 & 1 \\
\hline
\end{tabular}

Table 4: Test samples used for verification.

\begin{tabular}{lc}
\hline Damaged element & Damage severities \\
\hline Element 4 & $1 \%, 2 \%, 3 \%, 4 \%, 6 \%, 7 \%, 8 \%, 9 \%, 11 \%, 12 \%, 13 \%, 14 \%, 16 \%, 17 \%, 18 \%, 19 \%$ \\
\hline
\end{tabular}

\subsubsection{Numerical Results}

In order to verify the effectiveness of the proposed method, different damage severities of element 4 are used as testing samples. The damage severities are listed in Table 4 . These sixteen samples possess favorable representative.

The identification results are obtained through the calculation process of Section 2.6. The fuzzy nearnesses between eigenvector of each damage severity and rules in knowledge base is illustrated in Figure 7. It can be seen from Figure 7 that as the damage become more severe, the peak value of fuzzy nearnesses changes from "slight damage" to "severe damage." Therefore the fuzzy nearness-based method is a good pattern classifier, and it is applicable to damage identification of bridges.

The damage condition of each severity can be acquired based on approaching principle. The identification results are demonstrated in Figure 8. As can be seen from Figure 8 , the fuzzy nearness-based damage identification method can successfully identify all the test samples except damage severity $3 \%$, and the success rate is $93.75 \%$. It reveals that the proposed method in this paper possesses predominant inference ability.

The numerical results indicate that only the vector of IMSR for the first vertical bending mode is adequate to identify the damage condition of bridge. It reveals that the fuzzy nearness-based damage identification method is convenient and effective in application. 


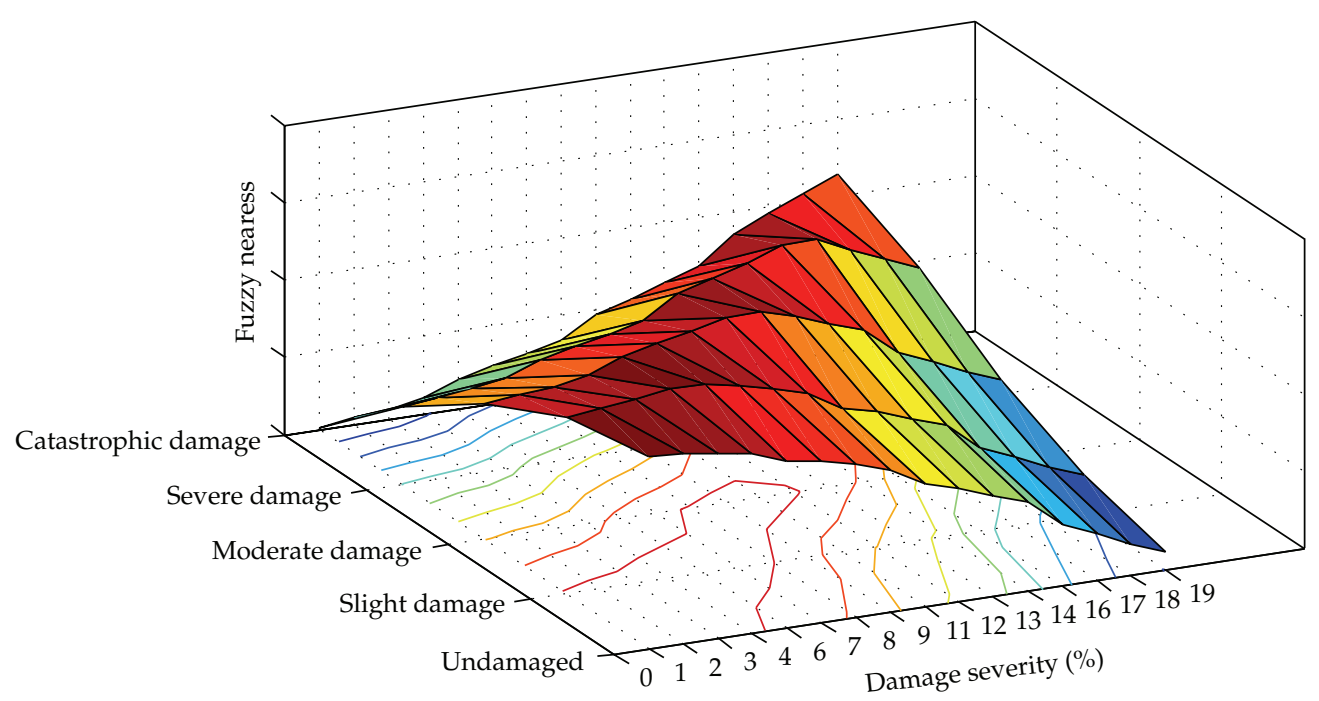

Figure 7: Fuzzy nearnesses between eigenvector of each damage severity and rules in knowledge base.

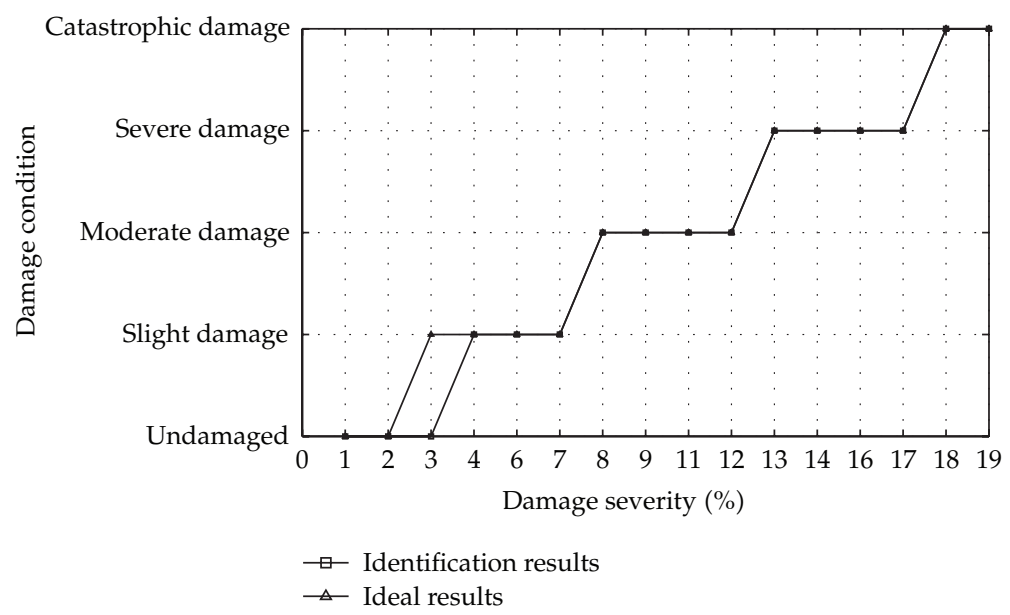

Figure 8: Identification results of fuzzy nearness-based method.

\subsubsection{Antinoise Analysis}

Taking the damage identification of element 4 with damage severity $16 \%$, for example, antinoise analysis was conducted for the proposed method by adding different noise levels $(\lambda)$ of $5 \%, 10 \%, 15 \%$, and $20 \%$ into the eigenvector. The identification results are demonstrated in Figure 9. The results show that the fuzzy nearness-based method can identify the damage condition up to $20 \%$ noise level. It indicates that the proposed method possesses favorable ability of dealing with uncertainties. 


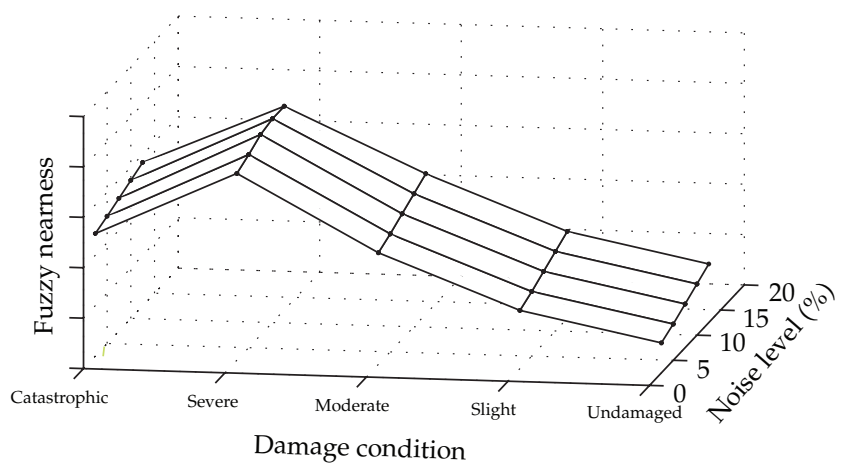

Figure 9: Antinoise analysis of fuzzy nearness-based method.

Table 5: Knowledge base for damage identification of missing information at node 32.

\begin{tabular}{lccccccc}
\hline $\begin{array}{l}\text { Slight } \\
\text { damage }\end{array}$ & $\begin{array}{c}\text { Moderate } \\
\text { damage }\end{array}$ & $\begin{array}{c}\text { Severe } \\
\text { damage }\end{array}$ & $\begin{array}{c}\text { Catastrophic } \\
\text { damage }\end{array}$ & $\begin{array}{c}\text { Slight } \\
\text { damage }\end{array}$ & $\begin{array}{c}\text { Moderate } \\
\text { damage }\end{array}$ & $\begin{array}{c}\text { Severe } \\
\text { damage }\end{array}$ & $\begin{array}{c}\text { Catastrophic } \\
\text { damage }\end{array}$ \\
\hline 0.1080 & 0.3177 & 0.6169 & 1 & 0.1048 & 0.3245 & 0.6138 & 1 \\
0.1051 & 0.3185 & 0.6144 & 1 & 0.1051 & 0.3185 & 0.6144 & 1 \\
0.1048 & 0.3245 & 0.6138 & 1 & 0.1080 & 0.3177 & 0.6169 & 1 \\
0.1125 & 0.3181 & 0.6213 & 1 & 0.1125 & 0.3181 & 0.6213 & 1 \\
0.1062 & 0.3194 & 0.6224 & 1 & 0.1062 & 0.3194 & 0.6224 & 1 \\
\hline
\end{tabular}

\subsubsection{Ability for Dealing with Incomplete Information}

In practical engineering, the information of modal shape at all nodes is not always available because of fault measurement or missing. Therefore, a discussion about the effect for dealing with incomplete information using the proposed method is necessary.

Also take the damage identification of element 4 with damage severity $16 \%$, for example, supposing that the mode shape at node 32 is missing. The damage identification is conducted only using the retained information at node 4, 5, 6, 14, 41. The knowledge base is listed in Table 5.

Test samples used for verification are listed in Table 4. The identification results are shown in Figure 10.

The identification results indicate that they are not affected by the missing information of node 32. Because the retained information at node 4, 5, 6, 14, 41 can still provide effective information of damage identification, the knowledge base is sufficient and feasible. Numerical simulation of element 4 with damage severity $16 \%$ reveals that the proposed method possesses favorable robustness.

\section{Conclusions}

We have presented a method to deal with uncertainties associated with measurement noise and incomplete information by means of fuzzy nearness and approaching principle. An improved index based on ratios of modal shape components is used as identification 


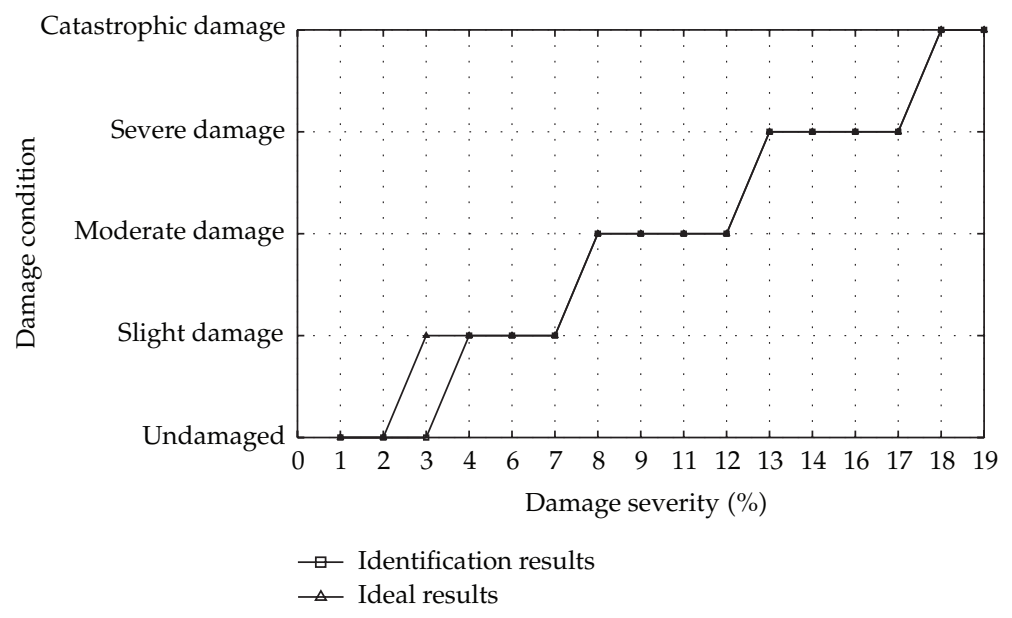

Figure 10: Identification results of fuzzy nearness-based method with incomplete information.

measurement. The IMSR for the first vertical bending mode of characteristic nodes is selected as the eigenvector for damage identification. The eigenvectors corresponding to damage conditions are fuzzified based on appropriate membership function, and the knowledge base is constructed. The damage condition of test sample can be determined by calculating its fuzzy nearness with rules in knowledge base by considering the approaching principle. A numerical simulation to identify damage in a simply supported bridge has been discussed. The results indicate that the proposed method is capable of identifying damage accurately. Anti-noise analysis and ability for dealing with incomplete information have verified its superiority to deal with uncertainties.

\section{Acknowledgments}

The authors gratefully acknowledge the support of the National High Technology Research and Development Program (863 program) of China (Project no. 2009AA11Z104), "985 Project" of the Jilin University, the support of innovation team program of Jilin University (2009-2010), and science frontier and interdiscipline innovation program of the Jilin University (20113145).

\section{References}

[1] S. W. Doebling, C. R. Farrar, M. B. Prime et al., "A review of damage identification methods that examine changes in dynamic properties," Shock and Vibration Digest, vol. 30, no. 2, pp. 91-105, 1998.

[2] E. P. Carden and P. Fanning, "Vibration based condition monitoring: a review," Structural Health Monitoring, vol. 3, no. 4, pp. 355-377, 2004.

[3] S. Hassiotis, "Identification of damage using natural frequencies and Markov parameters," Computers and Structures, vol. 74, no. 3, pp. 365-373, 2000.

[4] N. Stubbs, J. T. Kim, and K. Topole, "An efficient and robust algorithm for damage localization in offshore platforms," in Proceedings of the 10th ASCE Structures Congress, pp. 543-546, 1992.

[5] Q. Lu, G. Ren, and Y. Zhao, "Multiple damage location with flexibility curvature and relative frequency change for beam structures," Journal of Sound and Vibration, vol. 253, no. 5, pp. 1101-1114, 2002. 
[6] D. Wu and S. S. Law, "Sensitivity of uniform load surface curvature for damage identification in plate structures," Journal of Vibration and Acoustics, vol. 127, no. 1, pp. 84-91, 2005.

[7] M. M. A. Wahab and G. D. Roeck, "Damage detection in bridges using modal curvatures: application to a real damage scenario," Journal of Sound and Vibration, vol. 226, no. 2, pp. 217-235, 1999.

[8] R. Ganguli, "A fuzzy logic system for ground based structural health monitoring of a helicopter rotor using modal data," Journal of Intelligent Material Systems and Structures, vol. 12, no. 6, pp. 397-407, 2001.

[9] A. K. Pandey, M. Biswas, and M. M. Samman, "Damage detection from changes in curvature mode shapes," Journal of Sound and Vibration, vol. 145, no. 2, pp. 321-332, 1991.

[10] N. Stubbs and J. T. Kim, "Damage localization in structures without baseline modal parameters," AIAA Journal, vol. 34, no. 8, pp. 1644-1649, 1996.

[11] P. Z. Qiao, K. Lu, W. Lestari, and J. L. Wang, "Curvature mode shape-based damage detection in composite laminated plates," Composite Structures, vol. 80, no. 3, pp. 409-428, 2007.

[12] R. Palma, G. Rus, and R. Gallego, "Probabilistic inverse problem and system uncertainties for damage detection in piezoelectrics," Mechanics of Materials, vol. 41, no. 9, pp. 1000-1016, 2009.

[13] J. Argyris, M. Papadrakakis, and G. Stefanou, "Stochastic finite element analysis of shells," Computer Methods in Applied Mechanics and Engineering, vol. 191, no. 41-42, pp. 4781-4804, 2002.

[14] F. Bakhtiari-Nejad, A. Rahai, and A. Esfandiari, "A structural damage detection method using static noisy data," Engineering Structures, vol. 27, no. 12, pp. 1784-1793, 2005.

[15] P. Beena and R. Ganguli, "Structural damage detection using fuzzy cognitive maps and Hebbian learning," Applied Soft Computing Journal, vol. 11, no. 1, pp. 1014-1020, 2011.

[16] P. M. Pawar and R. Ganguli, "Genetic fuzzy system for online structural health monitoring of composite helicopter rotor blades," Mechanical Systems and Signal Processing, vol. 21, no. 5, pp. 22122236, 2007.

[17] M. Chandrashekhar and R. Ganguli, “Uncertainty handling in structural damage detection using fuzzy logic and probabilistic simulation," Mechanical Systems and Signal Processing, vol. 23, no. 2, pp. 384-404, 2009.

[18] Z. Zhao and C. Chen, "A fuzzy system for concrete bridge damage diagnosis," Computers and Structures, vol. 80, no. 7-8, pp. 629-641, 2002.

[19] M. M. Reda Taha and J. Lucero, “Damage identification for structural health monitoring using fuzzy pattern recognition," Engineering Structures, vol. 27, no. 12, pp. 1774-1783, 2005.

[20] R. Clough and J. Penzien, Dynamics of Structures, Prentice Hall, Upper Saddle River, NJ, USA, 2006.

[21] H. B. Liu, Y. B. Jiao, Y. C. Cheng, and Y. F. Gong, “Damage identification for simply supported beam bridge based on modal curvature theory and neural network," Journal of Jilin University Engineering and Technology Edition, vol. 41, no. 4, pp. 963-967, 2011. 


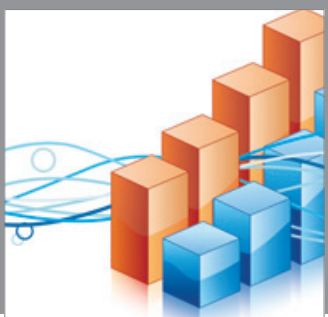

Advances in

Operations Research

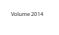

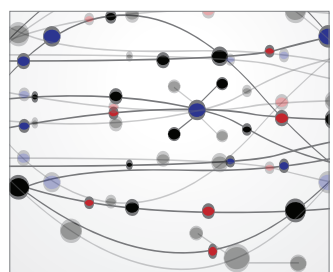

\section{The Scientific} World Journal
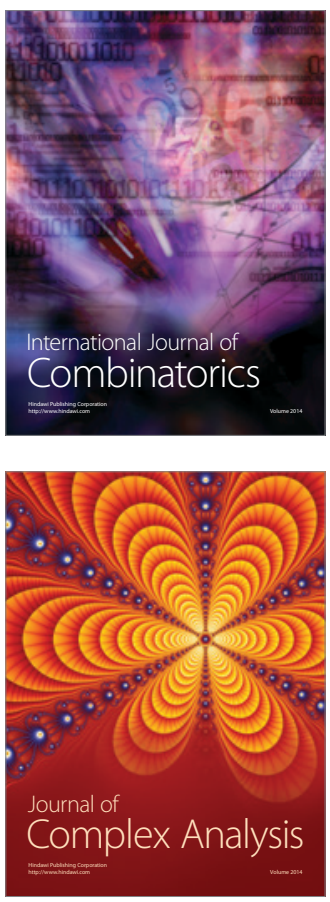

International Journal of

Mathematics and

Mathematical

Sciences
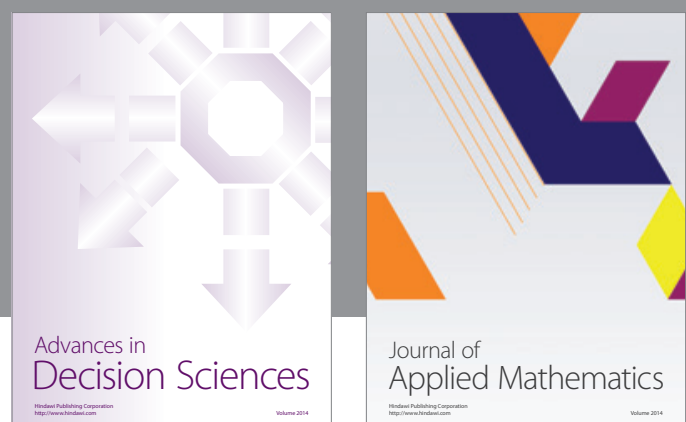

Journal of

Applied Mathematics
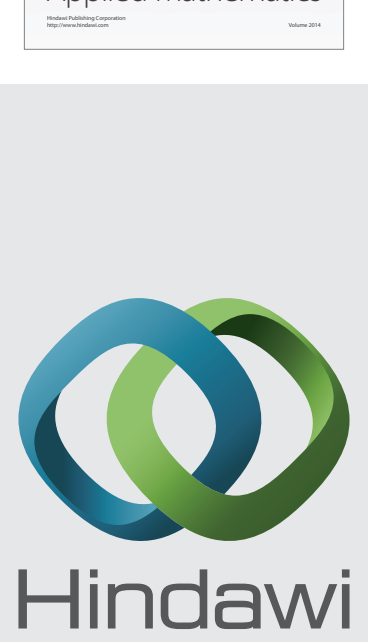

Submit your manuscripts at http://www.hindawi.com
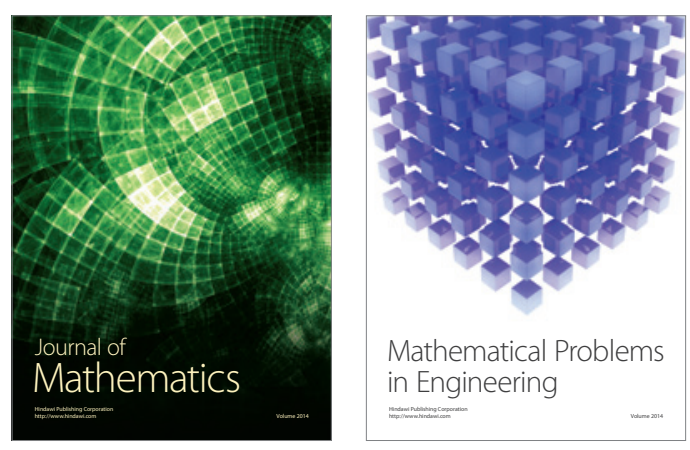

Mathematical Problems in Engineering
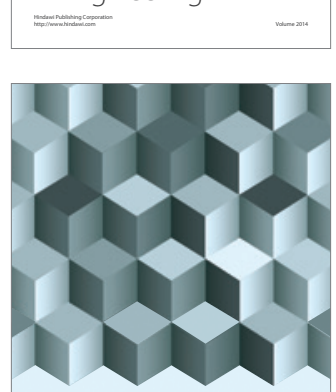

Journal of

Function Spaces
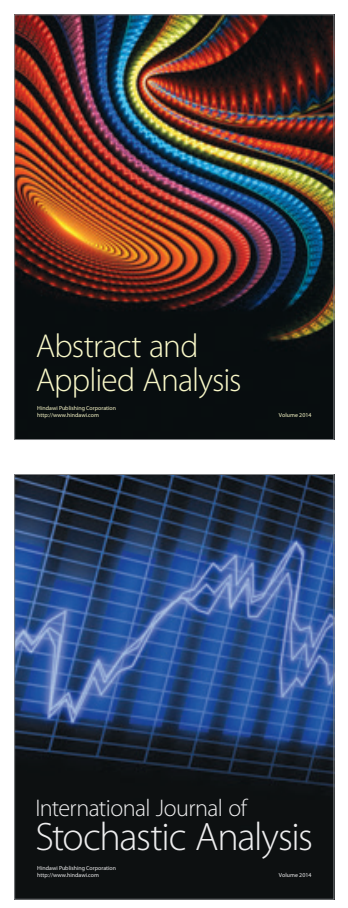

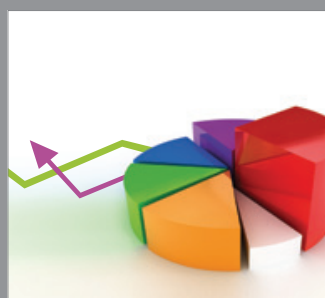

ournal of

Probability and Statistics

Promensencen
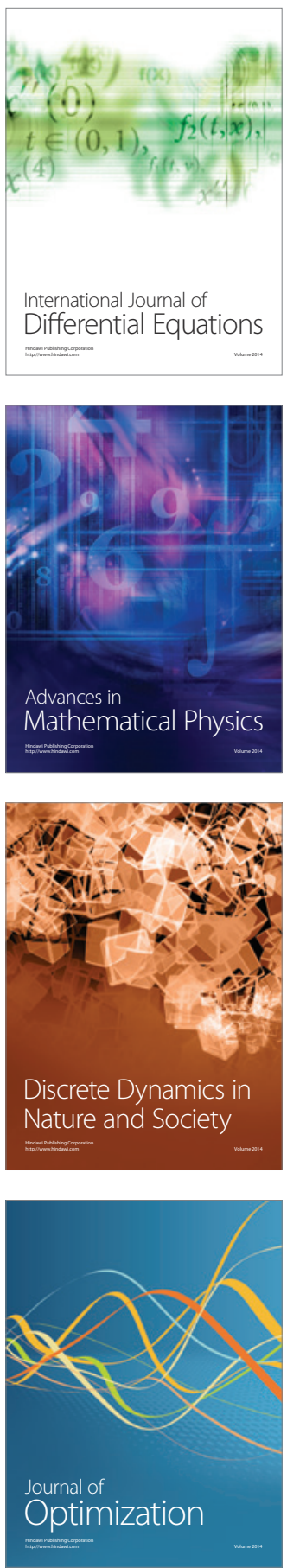